\title{
Study of Modes of Exit of Life - Insurance Policy Holders in Nigeria: Trends and Patterns
}

\author{
Dr. J. N. MOJEKWU \\ Department of Actuarial Science and Insurance \\ University of Lagos, Nigeria \\ Tel: 234-80-3306-3363Ｅ-mail: jnmoje@yahoo.com
}

Received: February 14, 2011 Accepted: February 26, 2011 doi:10.5539/ibr.v4n3p182

\begin{abstract}
Life Insurance contract is that under which one party pays a certain sum of money referred to as premium to another party in return on the happening of specified contingency (ices). These contingencies include: deaths, maturity, surrender lapsed and paid-up. These however, operate simultaneously as mutually exclusive events that impinge negatively on the life assurance portfolio.

Most life assurance policyholders complain of the adverse effect of inflation on the policy values at the time of payment on the happening of the contingencies. This has resulted in a high rate of lapse, surrender and conversion to paid-up status. This study therefore, investigates the effects of these multiple decrements on life assurance portfolios, which resulted in the hypothesis propounded and tested in this research. Based on the findings, the study recommends that life insurance companies should enlighten the public more on the benefits of life assurance and evolve some incentives so as to avoid the negative impact of these modes of decrement on life assurance portfolios.
\end{abstract}

Keywords: Modes of Exit, Life Insurance Policyholders and Life assurance Portfolio

\section{Introduction:}

Prior to the Nigerian independence in 1960, insurance companies in Africa were largely branches of overseas foreign companies who underwrote business locally and exported almost in whole premiums by way of reinsurance and repatriation of profits to their mother companies.

On attainment of independence between 1960 and 1975, African countries took over and largely nationalized their respective economic sectors. As a result, foreign-ousted companies became either out rightly state -owned parastatals or at best joint ventures between the state-its nationals and the former promoters.

Further development in the insurance industry witnessed most of the governments managing most of the insurance companies in Africa. Examples are the National Insurance Corporations of Ethiopia, Traumata, Uganda and Zambia among others. Also, monopolizing the industry is the state owned Reinsurance Corporation, which were legislated to guarantee income and secure a solid footing for growth. The same was the case with Ghana Reinsurance Organization, Kenya Reinsurance Corporation and Zimbabive Reinsurance Corporation Limited. The concept of life insurance can be described as a mechanism of risk transfer whereby the individual or group of people can shift some of the uncertainties of life to the shoulder of the operators of the business so as to be compensated on the happening of specified contingencies. As Adeleke (2000) puts it, life insurance operates on the principle of the sharing of losses among, those exposed to hazard of death.

Baily in Mojekwu (2001) pointed out that insurance companies are vital segments of the financial system in African countries and it is necessary to ensure their stability in order to maintain public confidence in the financial structure. Most African countries were using the United Kingdom assured lives and annuitant tables such as the $\mathrm{A}_{24-29}$, a (55), $\mathrm{A}_{49-52}$ rates which are rated up.

Life insurance companies for instance, deal with long-term as well as short-term plans. Consequently, it is necessary to safeguard the interest of the policyholders and promote national interest. According to Truyens (1996), in African only South Africa has developed mortality or annuity tables based on their country's experience.

Insurance companies in Nigeria have not been able to integrate customers' characteristics to its design process such that its services are not tailored towards customers' needs and desires. The Nigerian Reinsurance Corporation (1999) complained that most life insurance markets in Nigeria do not develop their own mortality tables, as a result, the claims meant for life - policy holders in Nigeria are still determined based on the mortality experiences of advanced 
countries which have different trends, patterns and causes of deaths from Nigerian experiences. Therefore in Nigeria, the mortality risk on which premiums are based is at best inappropriate and at worst completely wrong.

Mojekwu (2001) stated that the premium usually paid by the life-policy holders is viewed as an investment that ought to yield attractive returns. He however, lamented that in Nigeria where the returns are not comparable to the alternative investments like bank deposits, life-policyholders will view investment in life - assurances as wasted resources, if some steps are not taken.

It has been postulated in Mojekwu (2002) that Nigerian life - insurance companies do not enjoy good public image and that some members of the public seem to have no confidence in the industry resulting in the drastic changes in the trends and patterns of the modes of exit.

According to Salami (1996) existing customers claimed that they allow the policies to lapse due to poor premium pricing and poor relationship marketing on the side of the life policy operators. Furthermore, they complained that in Nigeria, premium charged in life assurance do not take cognisance of inflation rate. In most cases, the value of the sum assured which is payable would have been eroded by inflation in the economy. However, this nonincorporation of inflation factor into the returns on life-policy impacts negatively on the interest of potential life-policy holders thereby affecting the trends and patterns of the mode of exit. On the other hand, the life insurance operators argued that inflation is taken care of by issuing policies on the profit basis.

The age structure of a population has far reaching influence in the economy standard of any society. Such has been observed in the Nigerian society. The Federal Office of Statistics (1999) stated that the projected population of Nigeria for 1994,1995 and 1996 are 96,763,498, 99,501,902 and 102,317,806 respectively. On the other hand, Nigeria Demographic and Health survey (1999), placed Nigeria as one of Africa's most endowed economies, with abundance of both natural and human resources. Moreover, the main feature of the Nigerian economy has always been that a high proportion of the national income is derived from the export of a wide range of mineral and agricultural products, with crude oil currently taking the lead.

The country's balance of payments improved significantly in 1999 as a result of the rise in global oil prices. However, the performance of non-oil exports remained unimpressive; hence, the insurance industry is not an exception. Also, the Population Council (1996) revealed that Nigeria is by far the most populous nation African. The study also ranked Nigeria among the seven most populous countries in the world. There are beliefs that among every five Africans about are Nigerians. The officially accepted of Nigeria for 1963 stood at 55.7 million persons and in 1993, it increased to 98.5 million persons. This gives an increase of 70 percent over the past 30 years. Meanwhile, the projections for the future show that Nigeria could reach 108million by the year 2015. The history of the world population has not been a steady one. So the same goes for Africa as well as Nigeria.

\section{Objectives of the Study}

This study evaluates the factors responsible for the increased life - policy lapses in the Nigerian insurance industry. More specifically, efforts were made to examine the patterns of the modes of exit of policyholders from the contract. In addition, exits through death were compared with other modes of exit in order to portray the true picture of various modes of exit from a life assurance portfolio.

\section{Methodology}

The target population was all the insurance companies engaged in life-policy business in Nigeria. From this population, stratified sampling technique was first carried out by, grouping the entire population into four strata. The grouping was done according to the number of years each of the insurance companies has been in operation. At the second stage, one insurance company was randomly selected from each of the strata to form the study sample.

The period of observation of the assured lives was limited to between policy anniversaries in 1992 and the end of 1999. Policies previously issued, as well as those issued after 1999 were not considered because of the quality of such data with respect to the objective of the study. Also, the study covered only insuring population within the age bracket of 25 to 55 years. This approach offers credence to determining happenings in other African countries if the methodology is adopted. A comparison of results can then be carried out among developing countries.

\section{Data Analysis}

In an attempt to address the research question "Are the number of insured life reaching maturity different from the number of insured lives dropping on the way? The following hypothesis was formulated.

Ho: There are no significant differences between the average number of Life - policyholders reaching maturity and the average number of life - policyholders going out of the system among insured lives. 
From Table 1. It is observed that out of the sample of 2, 015 life policies extracted from the life policy registers, 462 did not reach maturity. Therefore, the proportion $(\mathrm{P})$ of policies not reaching maturity can be derived and represented as:

$$
P=\frac{462}{2,015}=0.23
$$

According to the Institute of Actuaries and Faculty of Actuaries (1976), the following notations $\left(\mathbf{n}_{\mathbf{x}}, \mathbf{l}_{\mathbf{x}}, \mathbf{s}_{\mathbf{x}}, \boldsymbol{\theta}_{\mathbf{x}}, \mathbf{e}_{\mathbf{x}}\right)$ could be used in the study. These notations are shown on table 1 and explained in the appendix.

Hence, the hypothesis was tested in section 3 using $\mathrm{z}$ - test for proportion and the result obtained revealed that a greater number of life - policyholders do not maintain their life policies up to maturity. That is the calculated value of $\mathrm{z}$ is 28.80 against the tabulated value of 1.96 .

$(\mathrm{z}-$ calculated $=28.80$ against $\mathrm{z}-$ tabulated $=1.96)$

Furthermore, Chi-squared statistic test was applied to examine the dependency of Age of the life -policyholders on the mode of exit from the life-policy contract as shown on Table 2.

\section{Discussion of Results}

In effect the result suggests that there are significant differences between the average number of life - policyholders going out of the system and the average number of life-policyholders reaching maturity in the contract. From this, one would conclude that a greater number of life-policy holders do not maintain their life - policies up to maturity.

Table 3 shows that out of the 2015 life-policyholders under investigation, 462 dropped out from the system during the period under study. This implies that about seventy seven percent of the life -policyholders were still in force by the end of the period under investigation. The table further shows that death $\left(\mathrm{o}_{\mathrm{x}}\right)$ has the least number of exits, with the highest number of deaths occurring within the age range $35-45$ years. On the other hand, the table shows that the rate of exit is highest within the age $25-35$ years. Lapse and surrender polices are identified as the commonest modes of exits. These two modes of exit also recorded the highest number of occurrences within the age group 25 -35 years. Also it is clearly shown on table 3 that those below thirty-five years of age who surrendered or allow their policies to lapse constitute more than 50 percent of the life policies considered during the study.

\section{Policy Implications of the Results}

However, the results support the notion that dependency exists between the ages of life-policyholders and their modes of quiting the life-policy contract. Hence, the mode of exit can be said to depend on the age of life-policyholder. Furthermore, the views harvested from the life-policy holders seem to suggest that young people rush to take up life-insurance policy and withdraw almost immediately because of the harsh and difficult economic situations prevalent in the Nigerian business environment (see table 3). Also the study revealed that life policyholders were more stable in maintaining their life - policy contract in the late nineties than in the early nineties. This is demonstrated in table 4.

Hence, we can derive from the study that the life - insurance operators need more efforts to make the public understand that insurance services are investments for the future and the perception that insurance services are a luxury should be discouraged.

In life assurance practice, sudden termination of life policy before maturity (lapsation) is always provided for in the non-forfeiture provisions whereby the policyholder is not disadvantaged if there is a change in his economic circumstances resulting in his inability to continue with premium payment.

As life insurance companies deal with long-term as well as short-term contracts, it is necessary to safeguard the interest of the policyholders and promote national interest. In some economies, premium on life assurance comes from discretionary income especially in the third world countries. The position may be little different in the advanced economies.

The loanable funds of the insurance industry will be on the increase and the interest rate on decrease if lapse ratio is on the increase provided such policies have not acquired any surrender value. On the other hand, if such policies have acquired surrender values, policyholders will not like to borrow but will reduce in number causing the rate to rise. In situation where life policies are converted to paid-up status, there will be more funds for lending which may lead to a drop in interest rate lower than the rate in the case of high lapse ration. There is usually an inverse correlation between the impact of lapsation and interest rates since lapsation is concerned with whole-life, pure endowment and endowment assurances.

It is suggested that life insurance companies should issue all life - polices on the basis of the effects of inflation as long term contract as this will go a long way to attract the public attention in general and the potential life policy 
holders in regaining their confidence in the life insurance industry in Nigeria. Finally, government has a part to play to promote and create total awareness to the public agreements on life insurance policies especially among the working class as the study revealed that there is very low level of awareness and understanding by the Nigerian public.

Development of insurance sector is important in developing the economy of any nation. Life insurance services have not been significantly accepted in developing countries such as Nigeria. The poor level of life insurance culture in Nigerian economy in particular has attracted relative interests among researchers.

There has not been continuity in the Nigerian government, which invariably affects the government policies. It is only when the political and socioeconomic institutions guiding the operations of insurance practices are protected against shocks from foreseen and unforeseen circumstances that the whole economy can grow and develop progressively.

\section{Conclusion}

Life assurance is a very important business which seems to have been misconstrued by the insuring public due to inflation and attitude of Nigerians. This lack of interest in investing in Life Assurance has retarded the development and the growth of Life Assurance business in Nigerian market. The policy rarely takes advantage of the none forfeiture provisions in the policy conditions which have resulted in high lapse rates and low persistence. Furthermore, there is with this is the prejudice about life insurance and the poor training of the field underwriters who are the backbone of insurance marketing.

In terms of investment, insurance industry seems to have no place in Nigeria. The unpredicted nature of our economic situation makes it look fraudulent on the eyes of the generality of the country. However, if the life assurance policies should be designed on the short-term basis, more people will be interested as revealed from the questionnaire administered.

Insurance companies therefore need to invest more in public enlightenment and manpower development so as to give life assurance business its pride of place in the economy

\section{References}

Adeleke, P. (2000). Practical strategies for Effective marketing of Insurance Products in Nigeria. The Nigerian Journal of Risk and Insurance, Vol. 2, No, 1, PP. 70-93

Federal Office of Statistic. (1999). National Social Indicators, F.O.S., Lagos, Nigeria.

Institute of Actuaries and Faculty of Actuaries. (1976). Continuous Mortality Investigation Reports Number 2, Cambridge. 178 PP.

Mojekwu, J.N. (2001). The Effects of Poor Premium on the Performance of Nigeria Insurance Industry Life Insurance. The Nigerian Journal of Risk and Insurance, Vol. 2, No 1, PP. 70 - 93.

Mojekwu, J,N. (2002). Modelling Life - Insurance Tables Based on mortality Patterns of Insured Nigerians. An unpublished Ph. D. Thesis, Department of mathematical science University of Agriculture, Abeokuta, Nigeria.

Nigerian Reinsurance Corporation. (1999). Nigerian Insurance Year Book, 1999 Edition, Lagos Nigeria.

Population Council. (1996). Population and Development Review. Vol.12 No1, March, 1996. U.S.A.

Salami, K. A. (1996). Development of life Business - Role of the African life Reinsure, African Insurance Organisation (AIO) Seminar on life Assurance, Mombasa, Kenya, No rember 27 - 28, PP 33 - 37.

Truyens, P. (1996). Life- Insurance in Africa. Past Products and Future Strategies. African Insurance Organisation, Mombasa Kenya, Novermber 27-28, Pp 33-37.

Volfson, M. (1996). Health - Adjusted Life Expectancy. Health Reports, 891): 41 - 5 Statistics Canada (at 82 - 003 -X P6) 
Table 1. Summary of Data From life-Policy Registers

(1992-1999)

\begin{tabular}{|c|c|c|c|c|c|}
\hline Age & $\mathbf{n}_{\mathbf{x}}$ & $\mathbf{l}_{\mathrm{x}}$ & $\mathbf{S}_{\mathbf{x}}$ & $\boldsymbol{\theta}_{\mathrm{x}}$ & $\mathbf{e}_{\mathbf{x}}$ \\
\hline 25 & 98 & 11 & 6 & 1 & 23 \\
\hline 26 & 72 & 3 & 5 & - & 17 \\
\hline 27 & 78 & 7 & 4 & 1 & 31 \\
\hline 28 & 114 & 16 & 5 & 1 & 40 \\
\hline 29 & 118 & 7 & 5 & - & 49 \\
\hline 30 & 174 & 31 & 4 & 2 & 76 \\
\hline 31 & 132 & 22 & 6 & 2 & 100 \\
\hline 32 & 141 & 21 & 7 & 2 & 134 \\
\hline 33 & 136 & 19 & 8 & 2 & 115 \\
\hline 34 & 125 & 17 & 12 & 3 & 108 \\
\hline 35 & 133 & 17 & 9 & 3 & 103 \\
\hline 36 & 102 & 19 & 6 & 3 & 98 \\
\hline 37 & 110 & 19 & 9 & 6 & 94 \\
\hline 38 & 75 & 8 & 2 & 7 & 84 \\
\hline 39 & 73 & 13 & 5 & 2 & 80 \\
\hline 40 & 72 & 15 & 4 & 2 & 73 \\
\hline 41 & 58 & 7 & 5 & 2 & 69 \\
\hline 42 & 39 & 4 & 4 & 3 & 46 \\
\hline 43 & 36 & 6 & 1 & 4 & 44 \\
\hline 44 & 26 & 7 & 2 & 2 & 33 \\
\hline 45 & 34 & 5 & 2 & 4 & 29 \\
\hline 46 & 14 & 3 & 2 & 2 & 29 \\
\hline 47 & 12 & 3 & 1 & 1 & 22 \\
\hline 48 & 15 & 2 & 1 & 1 & 12 \\
\hline 49 & 8 & 2 & - & - & 10 \\
\hline 50 & 9 & 1 & 2 & 1 & 7 \\
\hline 51 & 5 & - & - & - & 10 \\
\hline 52 & 3 & - & - & - & 5 \\
\hline 53 & 2 & - & - & 1 & 4 \\
\hline 54 & 1 & 2 & - & - & 5 \\
\hline 55 & - & - & - & - & 2 \\
\hline
\end{tabular}

Source: Mojekwu 2002

Table 2. Distribution ofF Age of Life-Policy Holders by Mode of Exit

\begin{tabular}{|c|c|c|c|c|c|c|c|}
\hline \multirow[t]{2}{*}{ Mode of Exit } & \multicolumn{2}{|l|}{ Lapse $\left(\mathbf{l}_{\mathrm{x}}\right)$} & \multicolumn{2}{|c|}{ Surrender $\left(e_{x}\right)$} & \multicolumn{2}{|l|}{ Death $\left(\theta_{x}\right)$} & \multirow[t]{2}{*}{ Total } \\
\hline & $\begin{array}{l}\text { Observed } \\
\text { (O) }\end{array}$ & $\begin{array}{l}\text { Expected } \\
\text { (E) }\end{array}$ & $\begin{array}{l}\text { Observed } \\
\text { (O) }\end{array}$ & $\begin{array}{l}\text { Expected } \\
\text { (E) }\end{array}$ & $\begin{array}{l}\text { Observed } \\
\text { (O) }\end{array}$ & $\begin{array}{l}\text { Expected } \\
\text { (E) }\end{array}$ & \\
\hline $25-30$ & 44 & 44.73 & 25 & 18.23 & 14 & 28.87 & 72 \\
\hline $30-35$ & 110 & 98.15 & 37 & 39.76 & & & 158 \\
\hline $35-40$ & 76 & 79.52 & 31 & 31.91 & 21 & 16.07 & 128 \\
\hline $40-45$ & 39 & 42.24 & 16 & 17.22 & 13 & 8.54 & 68 \\
\hline $45-55$ & 18 & 22.36 & 8 & 9.12 & 10 & 4.52 & 36 \\
\hline TOTAL & 287 & 287.0 & 117 & 117.0 & 58 & 58.0 & 462 \\
\hline
\end{tabular}

Source: Mojekwu 2002. 
Table 3. Distribution of Modes of Exit by Age

\begin{tabular}{|c|c|c|c|c|}
\hline Age & Lapse & Surrender & Death & Total \\
\hline $25-35$ & 154 & 62 & 14 & 230 \\
\hline $35-45$ & 115 & 47 & 34 & 196 \\
\hline $45-55$ & 18 & 8 & 10 & 36 \\
\hline Total & 287 & 117 & 58 & 462 \\
\hline
\end{tabular}

Source: Mojekwu 2002.

Table 4. Trends and Level of Awareness of Operations of Life Insurance Business

\begin{tabular}{|c|c|c|c|}
\hline $\begin{array}{l}\text { Meriod } \\
\text { of Life Policy }\end{array}$ & $\begin{array}{c}\text { Not } \\
\text { Matured }\end{array}$ & Matured & Total \\
\hline Before 1970 & 5 & 7 & 12 \\
\hline $1970-1979$ & 19 & 19 & 38 \\
\hline $1980-1989$ & 65 & 37 & 102 \\
\hline $1990-1999$ & 80 & 28 & 108 \\
\hline
\end{tabular}

Source: Mojekwu 2002.

\section{Appendices}

\section{Definition of Notations in Table I}

According to the Institute of Actuaries and Faculty of Actuaries (1976), the following notations were used in the study.

(i) Column $1(\mathrm{x})$ contains the age (x) of the Life-policy holder at the inception of the policy. This is derived by subtracting the year of birth from the year of policy inception.

(ii) Columns $2\left(n_{x}\right)$ is derived by collecting all those who were of age ' $x$ ' at the policy inception out of the 2,015 Life-policy holders under investigation.

(iii) Column $3\left(1_{\mathrm{x}}\right)$ is the collection of those life-policy holders who aged $\mathrm{x}$ at the time their policies lapsed.

(iv) Column $4\left(\mathrm{~S}_{\mathrm{x}}\right)$ is the collection of those life-policy holders who aged $\mathrm{x}$ at the time their policies were surrendered.

(v) Column 5: $\left(\theta_{\mathrm{x}}\right)$ is the collection of those life-policy holders who were of age $\mathrm{x}$ at the time of their death.

(vi) Column $6\left(\mathrm{e}_{\mathrm{x}}\right)$. This is derived by subtracting the year of birth of the life-policy holder from the year of valuation (1999) for policies still in force only. However, if the date of birth is before July 1, a unit is added to the result. This is because, the exposed to risk is calculated from tabulations by age nearest birthday of the policy inception in force on $1^{\text {st }}$ January and $31^{\text {st }}$ December 1999. This is also, under the assumption that with an investigation into mortality rates, we are concerned with a happening, which occurs only once for each insured life and where there is no element of duration of death. Hence, death is an instantaneous event. Rotationally, $e_{x}$ can be represented as,

$$
\mathrm{e}_{\mathrm{x}}=\left\{\begin{array}{l}
\text { (1999 minus year of birth) plus } 1 \text { if date of birth is before July. } \\
\text { (1999 minus year of birth) if year of birth is after July } 1 .
\end{array}\right.
$$

